Article

\title{
Crushed and River-Origin Sands Used as Aggregates in Repair Mortars
}

\author{
Maria Stefanidou \\ Thessaloniki 54124, Greece; stefan@civil.auth.gr; Tel./Fax:+30-2310-995-635 \\ Academic Editors: Carlos Alves and Jesus Martinez-Frias \\ Received: 21 January 2016; Accepted: 6 April 2016; Published: 13 April 2016
}

Laboratory of Building Materials, Civil Engineering Department, Aristotle University of Thessaloniki (AUTH),

\begin{abstract}
The systematic analysis of mortars from monuments or historic buildings and the simultaneous study of the construction environment show that it was common practice to use naturally occurring sand from local rivers or streams for the production of the mortars. There are cases though, mainly on islands, where sands of natural origin were limited, and marine or crushed sands were used possibly after elaboration. In all cases the particle size analysis of old mortar confirms the presence of even distribution of the granules. As regards the design of the repair mortars, there are criteria that should be taken into consideration in order to produce materials with compatible properties. The main properties concerning sands are the grain distribution and maximum size, the color, the content of fines, and soluble salts. The objective of this research is the study of the physical characteristics of the sands such as the sand equivalent, the gradation, the apparent density, the morphology of the grains, their mineralogical composition and the influence of these properties on the behavior of lime mortars, notably the mechanical and physical properties acquired.
\end{abstract}

Keywords: river sand; crushed sand; lime mortars; microstructure; strength

\section{Introduction}

Natural aggregates are the major components in building materials such as mortars. Aggregates are much cheaper in relation to binders and economy is achieved by using as much aggregate as possible in mortar mixtures. Also, their use improves both the volume stability and the durability of the composite materials considerably. Their physical characteristics, and in some cases their chemical composition, affect the properties of a mortar in both its plastic and hardened states to a varying degree [1]. The introduction of aggregates causes structural changes and affects macroscopic characteristics. Properties such as high porosity, inferior grading, round grains and coarse sands provoke porosity increase and the reduction of strength of the mortars due to the formation of loose contact zones between the aggregates and the mortar matrix [2,3]. When there is a chemical bond to the aggregates-paste transition zone, there is a good cohesiveness and the structure is characterized by continuity. The interlocking of the aggregate-paste forms the transition zone, which is characterized as the "weak" phase due to the high porosity and the formation of micro-cracks and different crystal sizes of the binder [4]. In construction, this means that stresses are transferred from one phase to another and there is a reduction of the shrinkage phenomena in relation to the pastes without the presence of the aggregates [5]. The incompatibility between the modulus of elasticity of the aggregate and that of the paste affects the development of micro-cracks at the aggregate-matrix interface. However, it is well recognized that coarse aggregate particles act as crack arresters, as they restrict the shrinkage of the binder, so that under an increasing load, extra energy is absorbed for the formation of a new crack $[6,7]$. Natural aggregates are readily available and their resources are nearly infinite. Potential sources exist in specific geologic environments and quality parameters are set by relevant regulations (EN933). 
Several studies have shown that aggregate behavior in mortar is influenced by composition [8,9], grain size $[9,10]$ form and texture $[9,11]$, and the percentage of fine particles [11,12].

Lime-based mortars have been used for centuries as the joint material of historic monuments of masonry constructions. Such mortars consist of binders (lime or a combination of lime and pozzolanic materials) and aggregates which are often coarse, especially in the case of masonry with thick joints [13,14]. The fact that the properties of aggregates influence the properties of lime mortars has been known since antiquity [8]. Even in old mortars, which were designed rather empirically, aggregates were used in different sizes such as 0-4 mm, 0-12 mm, 0-16 $\mathrm{mm}$ and 0-40 $\mathrm{mm}$ [2], and in even gradation so that the mortars were often characterized as "concretes" $[13,15]$. Natural aggregates used in historic mortars were sourced from rivers (usually they were easily extracted) and/or crushed aggregates (crushed rocks and crushed ceramics) [16]. Quarry sands were preferable, according to classic Roman writers such as Palladius, "as it sets easily", insisting that it must have no clay content [17]. In preparing mortars, the preferred aggregates were healthy, compact, of low porosity and smooth gradation, free of impurities and of high strength (Figure 1).

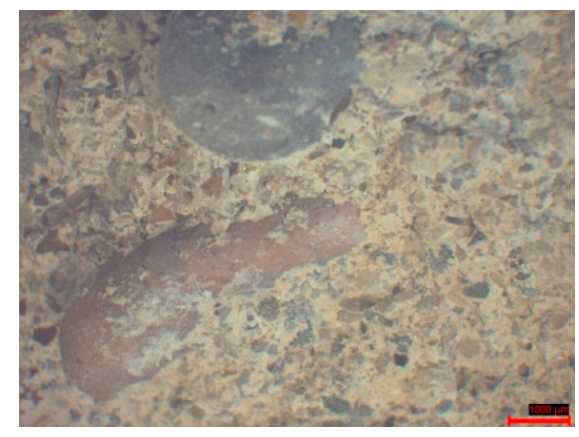

(a)

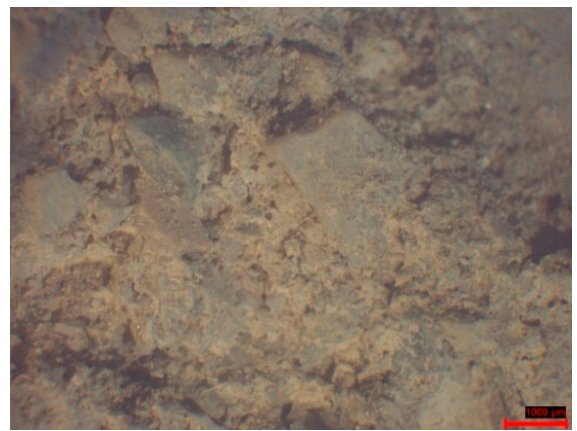

(b)

Figure 1. Historic mortars with (a) rounded aggregates and (b) angular aggregates.

The paper presents the results of a study concerning the manufacture of mortars based on lime with aggregates of different origin. The objective of this experimental work is the study of the physical characteristics of three sands including the sand equivalent, the apparent density, the morphology of the grains, their mineralogical composition and the influence of these properties on the behavior of the repair mortars, notably the mechanical and physical properties. The results of the paper could be a helpful guide for restorers in order to decide upon the use of aggregates when a repair mortar is designed.

\section{Experimental Work}

Two sands of natural origin coded A1 and A2 and one of crushed aggregates coded N1, which were of the same grain sizes $(0-4 \mathrm{~mm})$ that are available in the market and considered suitable for use in the composition of mortars, were used in order to produce lime mortars. The tests performed on the sands as raw materials concerned their gradation by sieving following EN 933-1, mineralogical control using XRD (Philips PW8040 diffractometer with Ni-filtered CuKa radiation), content of water-soluble salts with HPLC, determination of sand equivalent (SE) based on EN933-8:1999. The sand equivalent test quantifies the relative abundance of sand vs. clay and a higher sand equivalent value indicates that there is less clay-like material in a sample. Additionally, the apparent specific gravity and the porosity of sands were measured according to EN1097:2000 and determination of the geometrical characteristics of the sand grains using image analysis under a stereoscope (LEICA Wild M10) with ProgRes program was also performed. The two-dimensional images acquired were used in order to measure the sphericity which is given by: 
For spherical particles the value is equal to one, whereas for irregular grains the sphericity is smaller than one [18].

In relation to the produced mortars, the lime used was aerial (Type $\mathrm{N}$ according to ASTM206) and the binder/aggregate ratio (lime/sand) was $1 / 3$ by weight. The ratio of water/binder was 1.214 and was kept constant in order to study the effect of the sands on the workability of the mixture. The workability was tested by a flow table based on EN1015-3: 1999. The effects of the sands were tested on both fresh properties such as workability, and in the hardened state after curing in environment with $65 \% \mathrm{RH}$ and $20^{\circ} \mathrm{C}$. At the age of 28 days the mechanical and physical properties of the mortars specimens of $4 \mathrm{~cm} \times 4 \mathrm{~cm} \times 16 \mathrm{~cm}$ prisms were measured based on EN1015-11:1999 and RILEMCPC11.3, respectively. Additionally, the dynamic modulus of elasticity (Edyn) that describes the stiffness of the materials was calculated by ultrasounds based on BS1881-209:1990.

\section{Results}

\subsection{Tests on Sands}

The three sands tested present differences in color. N1 is yellow while A2 is darker in relation to A1 (Figure 2). The granulometry of the three samples is smooth, with A1 being the finest as Figure 3 shows, and there is a small difference in the content of the fine fraction $(<0.2 \mathrm{~mm})$ between the three sands. A1 contains 5\% fine particles whereas A2 and N1 contain less. The sands are of silica composition with small variations. Their mineralogical examination showed that A1 is silica sand with dominant minerals being quartz, opal, feldspar, calcite, magnetite and hornblende. In A2 sand, the predominant minerals are silica, quartz, feldspar, biotite, and hornblende, while in the yellow sand quartz, feldspar and magnetite prevail.

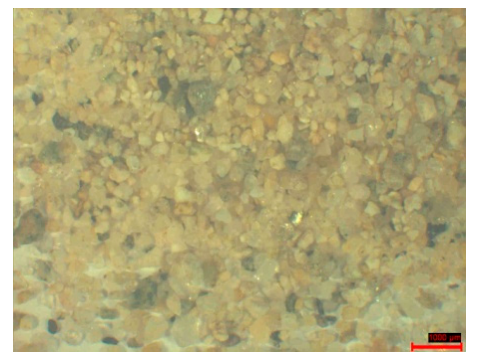

(A1)

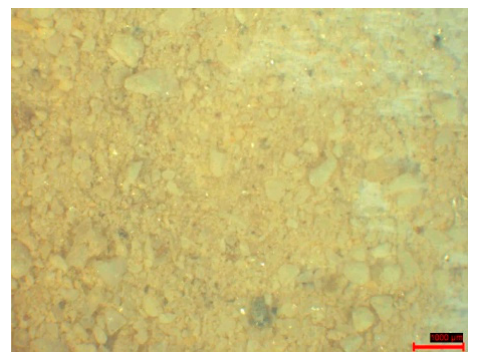

(N1)

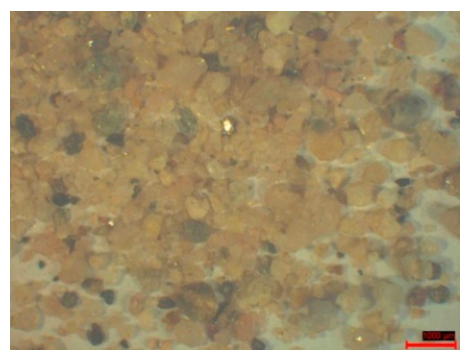

(A2)

Figure 2. A1 (left), N1 (middle) and A2 (right) under stereoscope.

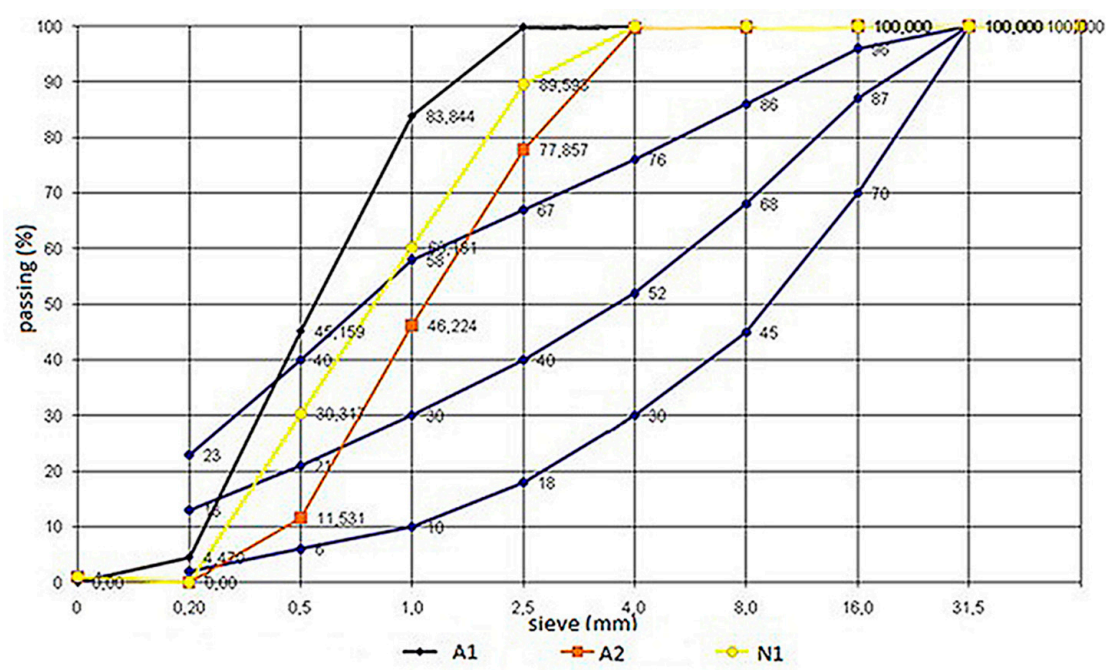

Figure 3. Gradation of the sands. 
The N1 sand has a low Sand Equivalent value (S.E.) which indicates impure aggregates and the existence of fine clay grain sizes. Also, it is characterized by moderate absorbency in relation to the other two materials, and it contains angular grains as the values of sphericity indicate (Table 1). The highest percentage of sand equivalent is presented in A1 sand, featuring material free of clayish content. This sand has low porosity and the grains are relatively spherical. The A2 sand is fine and presents high water absorption. Table 2 presents the soluble salts content and it can be concluded that all three samples show low salt content.

Table 1. Physical properties of the sands.

\begin{tabular}{ccccc}
\hline - & $\begin{array}{c}\text { Natural } \\
\text { Absorption (\%) }\end{array}$ & $\begin{array}{c}\text { App. Specific } \\
\text { Gravity (g/cm }\end{array}$ & S.E. & Sphericity \\
\hline A1 & 0.70 & 2.36 & 98.0 & 0.825 \\
A2 & 1.46 & 2.35 & 90.5 & 0.791 \\
N1 & 1.09 & 2.34 & 75.0 & 0.723 \\
\hline
\end{tabular}

Table 2. Soluble salt content of sands (\% by weight).

\begin{tabular}{cccc}
\hline- & $\mathrm{Cl}^{-}$ & $\mathrm{NO}^{-}$ & $\mathrm{SO}_{4}{ }^{2-}$ \\
\hline $\mathrm{A} 1$ & $<0.01$ & - & $<0.01$ \\
$\mathrm{~A} 2$ & $<0.01$ & - & 0.04 \\
$\mathrm{~N} 1$ & $<0.01$ & - & 0.01 \\
\hline
\end{tabular}

\subsection{Mortar Production}

The results regarding the gained properties of the mortars produced with the three tested sands are listed in Table 3. The tests have been performed on prisms of $4 \mathrm{~cm} \times 4 \mathrm{~cm} \times 16 \mathrm{~cm}$. Six samples were tested in each case and the mean values are reported. The mean values are generally low (below $1 \mathrm{MPa}$ compressive strength) but this was expected in pure lime mortars. Nevertheless, the mortars with N1 sand present higher strength and lower porosity than the mortars with the other two sands. This is probably due to the strong bonding that develops between the rough texture of the angular grains of N1 sand as evidenced by the microstructure study by SEM (Figure 4) [19]. Workability in this case is slightly smaller than in the mortars made with A1 and A2 sands using the same quantity of water, which is in agreement with the literature [20]. The mortars produced with natural sands present similar mechanical and physical properties in hardened state and also similar workability.

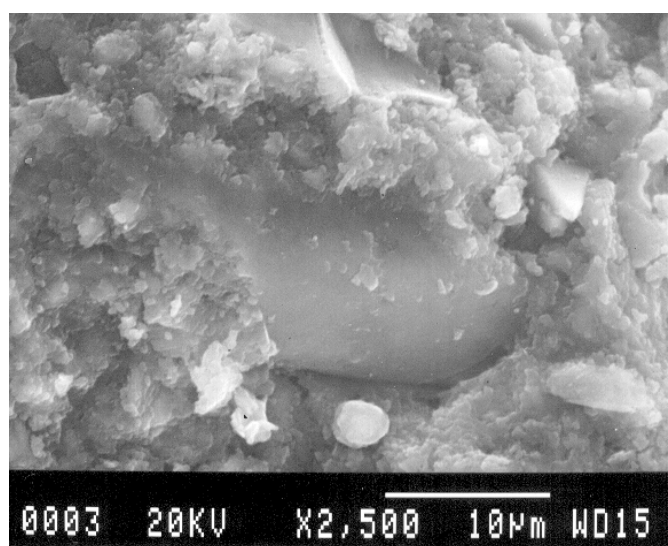

(A1)

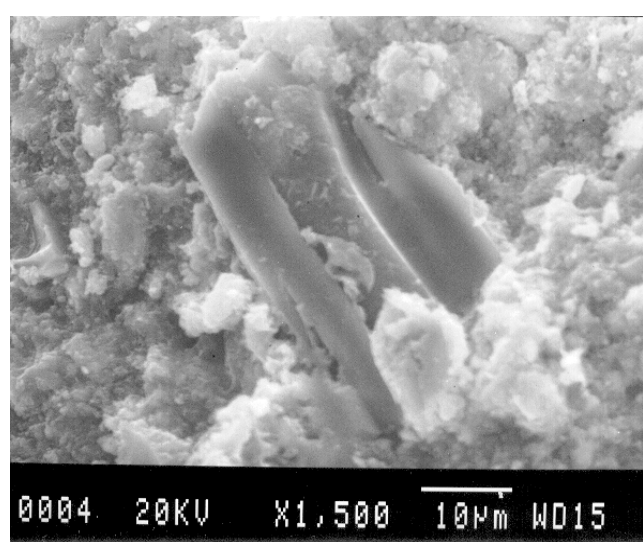

(N1)

Figure 4. Crack around the rounded grain of mortar with A1 sand (left) and strong cohesion between the binder and rough grain in a mortar with N1 sand (right). 
Table 3. Mechanical and physical properties of mortars at the age of 28 days.

\begin{tabular}{cccccc}
\hline - & Flexure (MPa) & Compressive (MPa) & Edyn (MPa) & Porosity (\%) & Workability (cm) \\
\hline A1 & 0.05 & 0.57 & 407.04 & 36.02 & 15.7 \\
A2 & 0.05 & 0.56 & 387.8 & 35.95 & 15.5 \\
N1 & 0.42 & 0.94 & 1586.4 & 35.02 & 14.8 \\
\hline
\end{tabular}

\subsection{Discussion}

After the completion of some physical, mineralogical and chemical tests on the three sand samples, it can be concluded that the granulometry of the sands presented small variations, with A1 being the finest. In all cases, the granulometry was smooth and no gap-graded cases were observed. All of them were silica-based sands but the morphology of the grains presented differences. They were free of soluble salts and were of similar apparent specific gravity. The sand equivalent values also presented some variations as well indicating that N1 sand contains clayish material. Despite that, the absorption of the N1 sand was moderate. The grains of N1 sand were angular in relation to the A1 and A2 sands, as it is crushed sand, compared to the river origin of the other two sands.

After recording these properties, three series of lime mortars were produced with the same binder/aggregate and binder/water proportions using the three sands as aggregates. It seems that the properties of the aggregates influence the properties of the mortars both in fresh and in hardened state. The water requirement is higher when aggregates with angular grains were used and it ensured greater consistency with the binder. The contained amount of clay existing in the crushed sand does not seem to harm the tested properties in mortars. Additionally, higher flexural and compressive strength and lower porosity were achieved with the angular sand. Small differences were recorded between the mortars prepared with the river sands.

\section{Conclusions}

Choosing natural, rounded or crushed, angular sand in repair mortars' composition is a multivariate decision influenced by parameters such as: the results of the analysis of the original mortars, the properties to be imparted to the new mortar (color, texture, porosity, strength) and the available materials. The compatibility of the repair mortars is essential for the aesthetic and functional role they have in a conservation work. It seems that the morphology of the sand grains affects the macroscopic properties of the mortars. Despite the higher water demand in mortars with crushed aggregates, the strength recorded was also higher due to the strong contact zone between the aggregates and the matrix.

In the case of river-origin sands, the two types tested in the present paper presented small variations in relation to their mineralogy while the A1 sand presented finer and more spherical grains. These properties resulted in a more workable mortar which presented sufficient mechanical and physical properties when hardened.

Conflicts of Interest: The author declare no conflict of interest.

\section{References}

1. Jackson, N.; Dhir, R.K. Concrete-aggregate. In Civil Engineering Materials, 5th ed.; Jackson, N., Dhir, R.K., Eds.; Macmillan: Basingstoke, UK, 1996; pp. 179-181.

2. Stefanidou, M.; Papayianni, I. The role of aggregates on the structure and properties of lime mortars. Cem. Concr. Compos. 2005, 27, 914-919. [CrossRef]

3. Tasong, W.A.; Lynsdale, C.J.; Cripps, J.C. Aggregate-cement paste interface: Influence of aggregate physical properties. Cem. Concr. Res. 1998, 28, 1453-1465. [CrossRef]

4. Neville, A.M. Admixtures. In Properties of Concrete Longman, 4th ed.; Prentice Hall Pearson Education: Washington, DC, USA, 1995; pp. 244-248.

5. Hobbs, D.W. Influence of aggregate restraint on the shrinkage of concrete. J. Proc. 1974, 71, 445-450. 
6. Kwan, A.K.; Fung, W.W. Packing density measurement and modeling of fine aggregate and mortar. Cem. Concr. Compos. 2009, 31, 349-357. [CrossRef]

7. Gonçalves, J.P.; Tavares, L.M.; Toledo Filho, R.D.; Fairbairn, E.M.R.; Cunha, E.R. Comparison of natural and manufactured fine aggregates in cement mortars. Cem. Concr. Res. 2007, 37, 924-932. [CrossRef]

8. Pavia, S.; Toomey, B. Influence of the aggregate quality on the physical properties of natural feebly-hydraulic lime mortars. Mater. Struct. 2008, 41, 559-569. [CrossRef]

9. Mahaut, F.; Mok, S.; Chateau, X.; Roussel, N.; Ovarlez, G. Effect of coarse particle volume fraction on the yield stress and thixotropy of cementitious materials. Cem. Concr. Res. 2008, 38, 1276-1285. [CrossRef]

10. Westerholm, M.; Lagerblad, B.; Forssberg, E. Rheological properties of micromortars containing fines from manufactured aggregates. Mater. Struct. 2007, 40, 615-625. [CrossRef]

11. Westerholm, M.; Lagerblad, B.; Silfwerbrand, J.; Forssberg, E. Influence of fine aggregate characteristics on the rheological properties of mortars. Cem. Concr. Compos. 2008, 30, 274-282. [CrossRef]

12. Mehta, P.K. Microstructure of Concrete. In Concrete, Structure, Properties and Materials; Hall, W.J., Ed.; Prentice Hall: Washington, DC, USA, 1986; pp. 44-50.

13. Pettifer, K. A Petrographic Investigation of Ancient Mortars and Concretes; NOTE No. N44/86, April 1986; Building Research Establishment: Watford, UK, 1986.

14. Bugini, R.; Salvatori, A.; Capannesi, G.; Sedda, A.F.; D’Agostini, C.; Giuiani, C.F. Investigation of the characteristics and properties of "cocciopesto" from the ancient roman period. In Proceedings of the 1993 RILEM Congress on Conservation of Stone and Other Materials, Paris, France, 29 June-1 July 1993; pp. 386-393.

15. Baronio, G.; Binda, L.; Lombardini, N. The role of brick pebbles and dust in conglomerates based on hydrated lime and crushed bricks. Constr. Build. Mater. 1997, 11,33-40. [CrossRef]

16. Lanas, J.; Alvarez-Galindo, J.I. Masonry repair lime based mortars: Factors affecting the mechanical behavior. Cem. Concr. Res. 2003, 33, 1867-1876. [CrossRef]

17. Martin, R. Les Belles Letres; Palladius Traite D' Agriculture Livre I. Societe D'Edition 1976; Bibliothèque Nationale: Paris, France, 1976. (In French)

18. Cox, M.R.; Budhu, M. A practical approach to grain shape quantification. Eng. Geol. 2008, 96, 1-16. [CrossRef]

19. Hong, L.; Gu, X.; Lin, F. Influence of aggregate surface roughness on mechanical properties. Constr. Build. Mater. 2014, 65, 338-349. [CrossRef]

20. De Schutter, G.; Poppe, A.-M. Quantification of the water demand of sand in mortar. Constr. Build. Mater. 2004, 18, 517-521. [CrossRef]

(C) 2016 by the author; licensee MDPI, Basel, Switzerland. This article is an open access article distributed under the terms and conditions of the Creative Commons Attribution (CC-BY) license (http://creativecommons.org/licenses/by/4.0/). 